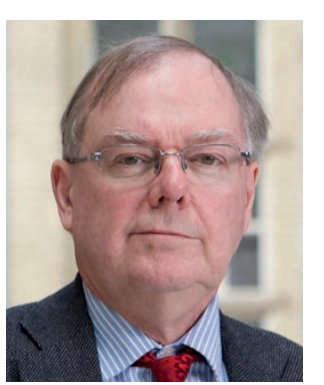

\title{
Social sciences lose out again in Common Rule reform
}

\section{The Common Rule's incoherent approach to ethics regulation will change little in the way institutional review boards and researchers interact, says Robert Dingwall.}

$\mathrm{E}$ thics regulation is difficult to get right. The protection of human subjects must be balanced against the creation of areas of ignorance, encroachment on academic freedom, a chilling effect on innovation, and paternalist denial of participants' rights to self-determination.

The Common Rule is a regulation that was first adopted in 1991 by most US federal agencies that commission or fund research. It provides a legal basis for the work of institutional review boards (IRBs) in governing ethical aspects of federally funded research. The Common Rule originated in a 1966 policy for Public Health Service grants, responding to the abuse of participants in biomedical research. That policy became a health department regulation in 1974, following further revelations of abuse. Other agencies were subsequently invited to join in creating a shared regulation but the health department has retained leadership.

Social scientists have long complained about the impact of the Common Rule and its precursors. These required the same review processes as those applied to biomedical research, despite the differences in their risk/ benefit profiles. Ordinary people manage the risks of disclosing personal or sensitive information every day. Social science research does not ask them to make complex technical or scientific judgements. No one will inject them with substances that could prove irreversibly toxic or deny them potentially life-saving benefits by randomization into a control group. Social science data is often collected in public settings or from administrative records. Where research involves asking questions or entering private spaces, social scientists cannot prevent people from falling silent, walking away or closing doors. However, the risk aversion and biomedical dominance enshrined in the Common Rule generated many experiences of heavy-handed and ill-informed assessments by IRBs. These decisions often reflected underlying methodological prejudices or reputational issues for institutions as much as genuine ethical concerns.

In 2011, the federal agencies announced a comprehensive review of the Common Rule.
Social scientists' hopes of sensible reforms were initially raised by a 2014 report of the National Research Council of the National Academies (NRC) and by the draft regulations issued for consultation in 2016. However, the revision process provoked a major controversy over whether patient consent should be required for access to biospecimens. It appears the authors of the final rule focused on managing this controversy. Other areas where there was disagreement or possible substantial change were left untouched or dealt with superficially. The social sciences, in particular, have been short-changed yet again.

The NRC set out a coherent approach that identified virtually all social science research as minimal risk. Such research should be 'excused' from ethical regulation on the basis that participants are able to make their own risk assessments regarding participation. A small number of experimental or intervention studies might require IRB review but everything else would just be registered. Specific consent would not be required for most studies - it could be inferred from willingness to fill in a survey or to continue with an interview or focus group. Observations in public spaces, including social media, would also be 'excused', as would most reuse of administrative datasets. 'Vulnerable groups' would no longer be listed and assumed to be capable of judging their own best interests. This approach was largely adopted by the draft regulations, which replaced the term 'excused' with 'excluded'. IRBs would lose their jurisdiction over most social science research, unless it fell within narrow criteria or they could justify calling it in from the registration documents. There were still uncertainties about the status of participant observation or ethnography, but the approach was broadly welcomed by the community.

This deregulatory spirit has been largely abandoned in the final text. Some work has been defined as 'not research' and taken out of the process. Most social science research has been left in the 'exempt' category as before. Where 'exclusion' would have removed most social science research from IRB jurisdiction, the definition of 'exemption' has not changed and nothing in the regulation prevents the continuing practice of IRBs requiring documentation to make the case that their jurisdiction should not be applied. The results are incoherent and unlikely to reduce the mistrust between social scientists and ethics regulators. A life history interview by an oral historian, for example, leading to the publication of individually identifiable material is not research and not subject to IRB review. A biographical interview by a sociologist or anthropologist, to be anonymized as a contribution to a generalized account of a structural or cultural matter, will be reviewable. A law professor who interviews participants in a particular case is not doing research. A social science professor doing exactly the same thing is reviewable.

The NRC report and the draft regulations defined social media as a public space where research should not be regulated - a matter of debate within the digital research community. The final text is silent on this important point. The proposals to give greater respect to the autonomy of 'vulnerable' groups in making their own decisions about taking part in social science research have been diluted: ethics regulation retains its paternalist character. There is some progress on documenting consent, social scientists will be allowed to infer this from continued participation as the NRC suggested.

The new regulation is still vulnerable to Republican plans for further review of all regulations issued in the last six months of the Obama presidency. Social scientists should press the case for the new administration's deregulatory impulses to apply here. Ethics regulation in the social sciences must be separated out and approached in a more coherent, principled and proportionate fashion.

Robert Dingwall is at Dingwall Enterprises Ltd., 109 Bramcote Lane, Nottingham NG8 2NJ, UK and at Nottingham Trent University, 50 Shakespeare Street, Nottingham NG1 4FQ, UK.

e-mail: robert.dingwall@ntlworld.com

\section{Competing interests}

The author declares no competing interests. 